\title{
The effect of circular bridge piers with different inclination angles toward downstream on scour
}

\author{
MOHAMMAD VAGHEFI ${ }^{1, *}$, MASOUD GHODSIAN $^{2}$ and \\ SAEID SALIMI ${ }^{3}$ \\ ${ }^{1}$ Department of Civil Engineering, Persian Gulf University, Shahid Mahini Street, P.O. Box: 75169-13817, \\ Bushehr, Iran \\ ${ }^{2}$ Water Engineering Research Center, Tarbiat Modares University, \\ 11114115 Tehran, Iran \\ ${ }^{3}$ Department of Civil Engineering, Tarbiat Modares University, \\ 11114115 Tehran, Iran \\ e-mail: vaghefi@pgu.ac.ir; ghods@modares.ac.ir; salimi.80@gmail.com
}

MS received 11 March 2015; revised 28 May 2015; accepted 20 July 2015

\begin{abstract}
A fundamental principle in the safe design of bridge piers is to estimate maximum scour depth. As such, many researchers devoted their efforts to study the phenomenon of scour around bridge piers and to present relationships to estimate maximum scour depth. In the current research, scour around circular bridge piers with two different diameters and different inclination angles toward downstream has been investigated experimentally under clear water and different discharges. The obtained results revealed that increase in the inclination angle leads to a significant decrease in the scour depth, dimensions of sediment ridge and scour hole. Moreover, by comparing the data obtained from vertical bridge pier and well-known relationships, a relationship having the most agreement with the results was selected and modified to estimate equilibrium scour depth around inclined piers.
\end{abstract}

Keywords. Scour; inclined bridge piers; clear water; uniform sedimentation.

\section{Introduction}

Placement of a bridge pier in the direction of water flow causes to form a complex three-dimensional flow around pier which has enough strength for the erosion of bed around pier (figure 1).

The pattern of produced flow includes down flow around pier nose, horseshoe vortex, surface vortex wake vortex. As a result of this complicated mechanism, a hole will gradually create around pier if the foundation is not properly designed. This may result in serious damage and even failure of bridge deck. Due to the severe consequences associated with this phenomenon, it has been the focus of a significant amount of studies within the last decades. These studies mainly include investigation of the effect of pier, flow conditions and sediment characteristics on the scour around vertical piers. Yet not too many studies have been conducted in relation with inclined pier subjected to water flow. Largely due to the advances in design and implementation of unordinary structures in the civil engineering in the last few years, the possibility of constructing such structures is realistic.

${ }^{*}$ For correspondence
In addition to above, unknown effects of scour on the flow around pier have received noticeable attention (figure 2).

Dey [1] investigated the three-dimensional flow field around a circular cylinder in a quasi-equilibrium scour hole under a clear water regime. He studied the distribution patterns of tangential, radial and vertical components of velocity upstream and longitudinal component of velocity downstream era cylinder. The flow simulation results show the existence of a helical motion of fluid around the cylinder. Dey [2] presented a theoretical model to estimate the timevariation of scour depth in an evolving scour hole at circular piers under clear-water and live-bed scour conditions with uniform and non-uniform sediments. The procedure developed for computing the time-variation of scour depth was based on the concept of the conservation of the mass of sediment, considering the horseshoe vortex system to be the main agent of scouring and assuming a layer-by-layer scouring process. Their computation was extended up to the equilibrium scour condition and the corresponding design formula for estimation of maximum scour depth was also proposed for given flow, sediment and pier conditions. The computed values of maximum scour depth showed adequate and safe estimation for bridge pier foundations. Muzzammil et al [3] carried out an experimental investigation to study 


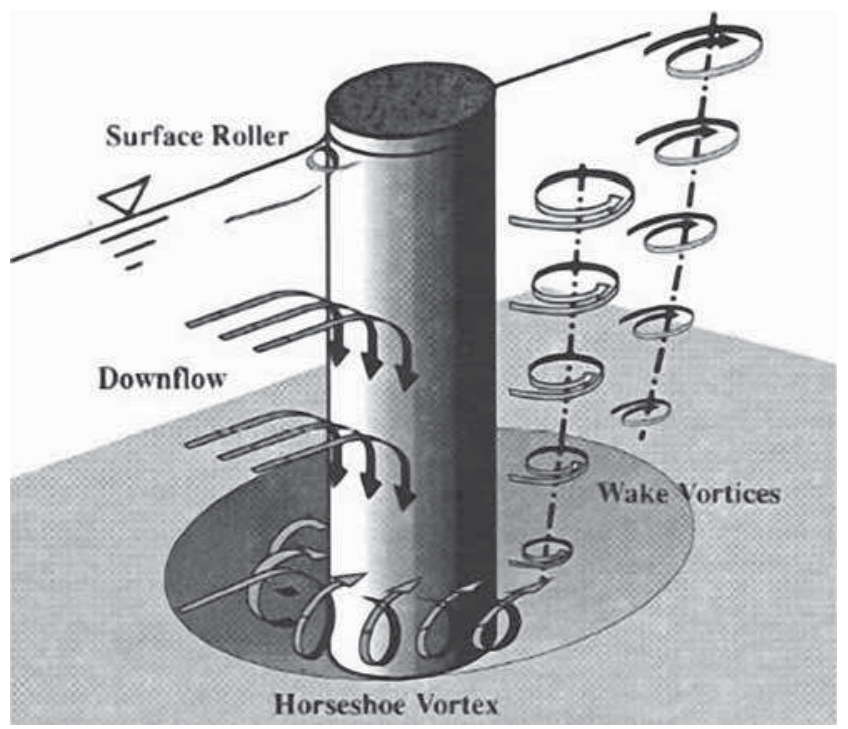

Figure 1. Schematic view of flow pattern around circular bridge piers.

the dominant features of the horseshoe vortex during the scouring processes. They found that the shape of the primary horseshoe vortex is dependent on the pier Reynolds number $\left(\mathrm{R}_{\mathrm{eD}}\right)$. The vortex is of circular shape only at lower Reynolds numbers $\left(\mathrm{R}_{\mathrm{eD}} \leq 5000\right)$, but it becomes more and more elliptical as $\mathrm{R}_{\mathrm{eD}}$ increases. Moreover, the results showed that the size of the vortex increases with the development of the scour hole whereas its elliptical shape remains fairly invariant during the scouring process. The mean velocity of the vortex is approximately $50 \%$ of the mean approach flow velocity on the rigid bed for $10^{4} \leq \mathrm{R}_{\mathrm{eD}} \leq 1.4 \times 10^{5}$. Bozkus \& Yaldiz [4] examined the effect of inclination of bridge piers on scour depth. Their tests involve an inclined pier toward the downstream direction under the angles of $2^{\circ}, 5^{\circ}, 10^{\circ}$ and $15^{\circ}$ and flow conditions limited to $0.49 \leq \mathrm{Fr}$ $\leq 0.55$ and $1.21 \leq V / V_{\mathrm{c}} \leq 1.86$ (Fr and $V / V_{\mathrm{c}}$ are Froude number and ratio of flow velocity to critical velocity, respectively). Bridge pier is made of Plexiglass with two different diameters (50 and $100 \mathrm{~mm}$ ) and uniform non-cohesive sediments are composed of particles with $d_{50}=0.5 \mathrm{~mm}$ and $d_{90}=1 \mathrm{~mm}$. In this paper, the results of 44 tests have been

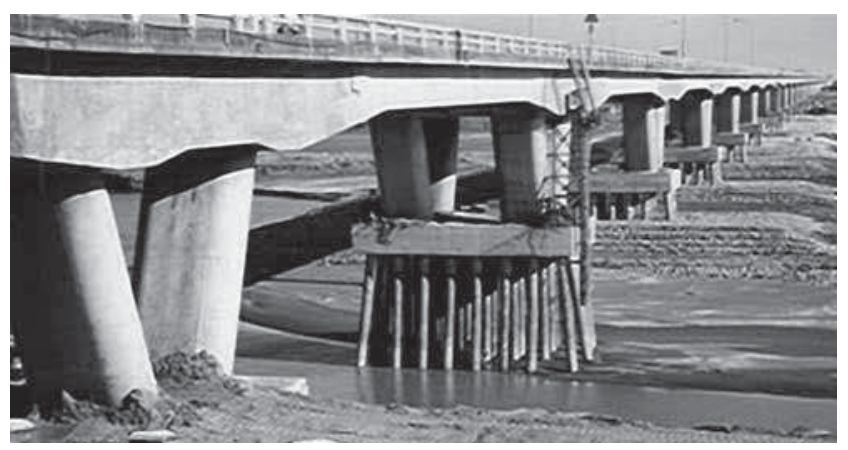

Figure 2. Bridge with inclined piers. evaluated within unusual equilibrium time of $120 \mathrm{~min}$. They concluded that scour depth decreases as the inclination of pier increases and also proposed a dimensionless relationship using dimensional analysis. The amount of coefficients and exponents in this relationship are presented separately for four considered angles. Lee et al [5] applied the backpropagation neural network (BPN) to predict the scour depth in order to overcome the problem of exclusive and the nonlinear relationships. The observations obtained from 13 states in USA were verified by the model. From the comparison with conventional experimental methods, they found that the scour depth around bridge piers can be efficiently predicted using the BPN. Lee \& Sturm [6] investigated the effect of relative sediment size on pier scour depth using three uniform sediment sizes and three bridge pier designs at different geometric model scales. They used Acoustic Doppler Velocimeter to measure flow around bridge pier. Observations of sediment movement, probability distributions of velocity components, and phase-averaging of velocity measured upstream of a bridge pier reveal properties of coherent motions that are discussed in terms of their contribution to the relationship between dimensionless pier scour depth and the ratio of pier width to sediment size over a large range of physical scales. Izadinia et al [7] measured the velocities around the bridge pier in three dimensions using an Acoustic Doppler Velocimeter. Quadrant analysis is used to recognize the susceptible regions for sediment entrainment and deposition. According to quadrant analysis sedimentation is the dominant effect in the scour hole whereas at higher levels the erosion force becomes more important. In downstream of the pier, sediment particles are put in suspension and transported downstream due to sweep. The results indicate that the secondary currents are more dominant in downstream of the pier, as compared to the upstream of the pier. Khosronejad et al [8] carried out experiments and numerical simulations to study clear-water scour around three bridge piers with cylindrical, square, and diamond cross-sectional shape, respectively. They studied about grid sensitivity to investigate the effect of grid resolution on the predictive capability of the model. Comparisons of the simulations with the experimental data showed that for all three cases the agreement was reasonable. Keshavarzi et al [9] investigated the coherent turbulent flow around a single circular bridge pier and its effects on the bed scouring pattern. They measured the three-dimensional velocity of flow at 102 points near the bed of an open channel using an Acoustic Doppler Velocity meter (Micro-ADV). The pattern of bed scouring was measured during the experiment. The velocity data were analyzed using the Markov process to investigate the sequential occurrence of bursting events and to determine the transition probability of the bursting events. The results showed that external sweep and internal ejection events were an effective mechanism for sediment entrainment around a single circular bridge pier. Aghaee-Shalmani $\&$ Hakimzadeh [10] presented the experimental results of scour around semi-conical piers to show the effect of their 
lateral slopes on the scour depth under steady current. The results showed that the scour depth of the pier with circular section with the largest lateral slope angle was reduced about 36 and $53 \%$ at the upstream and downstream sides of the pier in comparison with those of the circular cylinder, respectively.

Evidently, there have been few studies done on scour in the vicinity of the inclination bridge truss under the influence of different parameters; therefore, this study was conducted under clear water flow conditions with different discharges and the effects of inclination of piers have been discussed at initial motion and using equilibrium time. The results obtained from the inclined piers have been compared with those from vertical piers at the same test conditions. Moreover, by comparing data obtained from vertical bridge pier and well-known relationships, a relationship having the most agreement with the results was selected and modified to estimate equilibrium scour depth around inclined piers.

\section{Experiments and setup}

The experiments were conducted in the hydraulic laboratory of the Tarbiat Modares University in a straight rectangular channel with the length of $13 \mathrm{~m}$, width of $0.6 \mathrm{~m}$ and longitudinal slope of 0.002 (figure 3 ). The water was pumped into the channel from underground storage tank and the discharge was measured using V-Notch weir. The depth of water is adjusted using a gate located at the end of channel. In order to measure the depth and record bed profile, a digital depth gauge with the accuracy of $0.01 \mathrm{~mm}$ has been employed. According to Chiew \& Melville [11], pier diameter should be less than 0.1 time of channel width so that lateral walls have no effect on the obtained results. Consequently, PVC pipe with diameters of 4 and $5 \mathrm{~cm}$ was utilized for pier modeling. The pier was placed at one-third of the channel to ensure forming a uniform velocity profile along the channel length before reaching the flow close to pier.

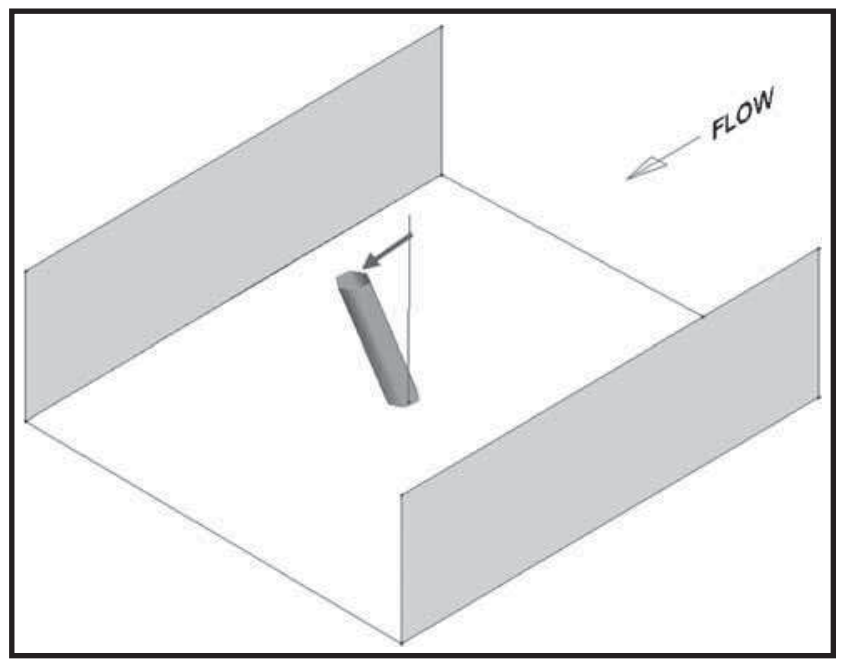

Figure 4. Schematic view of inclination piers into downstream.

Also, Ettema [12] recommended that the ratio of pier diameter to mean diameter of bed material should be greater than 50 so as to eliminate the effect of mean diameter of particles. Therefore, uniform sediment with the mean diameter of $0.6 \mathrm{~mm}$ was used in the tests to meet the mentioned requirement. According to Raudkivi \& Ettema [13], mean diameter of particles should be greater than $0.7 \mathrm{~mm}$ to prevent ripple. However, because no deformation was observed in the upstream bed during initial motion, sediment with the thickness of $18 \mathrm{~cm}$ was employed in the tests.

Melville [14] suggested that the ratio of flow depth to pier diameter should be assumed greater than 3-4 so that the effect of flow depth on the scour can be ignored. Thus, all tests were performed under clear water flow and four different ratios of $V / V_{\mathrm{c}}$ in a depth more than $18 \mathrm{~cm}$.

To study the effect of inclination angle on the scour depth, inclination angle of $21^{\circ}$ toward downstream was taken for the tests and the inclination angles of pier were considered with equal distances of $7^{\circ}$ and $14^{\circ}$ (figure 4 ).

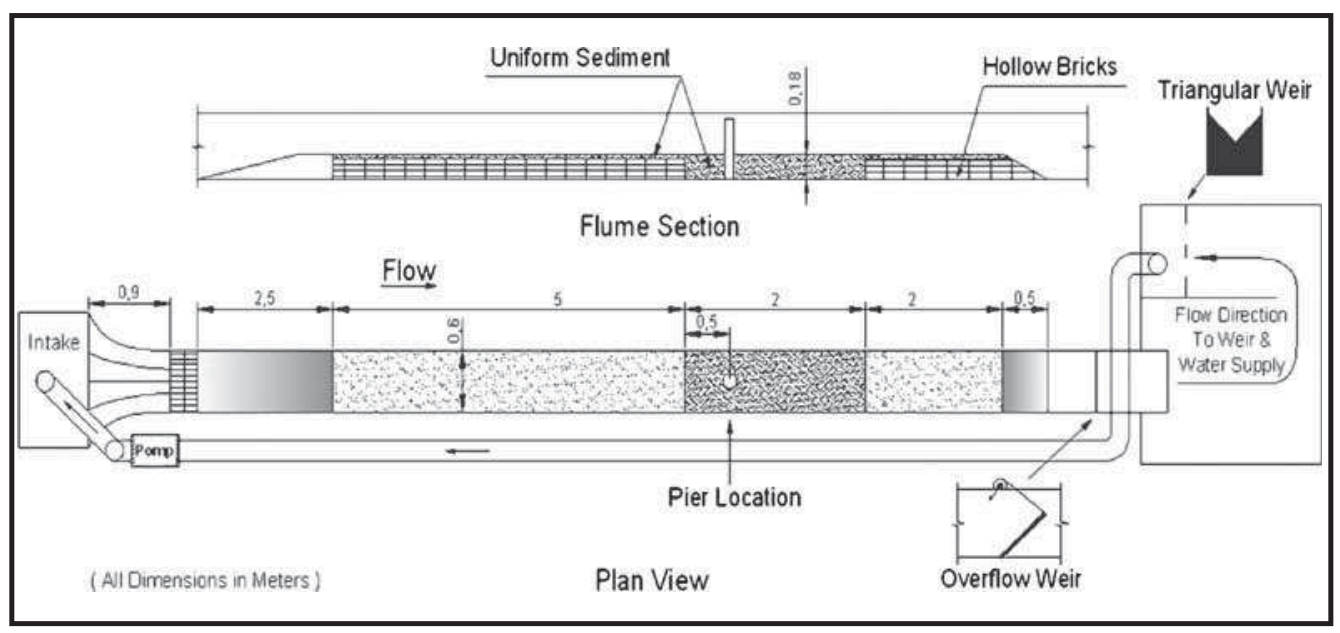

Figure 3. Schematic view of straight channel. 
Table 1. The program of experiments.

\begin{tabular}{|c|c|c|c|c|c|c|c|}
\hline \multirow{2}{*}{$\begin{array}{l}\text { No. of } \\
\text { experiment }\end{array}$} & \multirow[b]{2}{*}{$D(\mathrm{~mm})$} & \multirow[b]{2}{*}{$\beta$ (Deg.) } & \multirow{2}{*}{\multicolumn{2}{|c|}{$\begin{array}{c}\text { No. of } \\
\text { experiment }\end{array}$}} & \multirow[b]{2}{*}{$D(\mathrm{~mm})$} & \multirow[b]{2}{*}{$\beta$ (Deg.) } & \multirow[b]{2}{*}{$\frac{V}{V_{C}}$} \\
\hline & & & & & & & \\
\hline 1 & 40 & 0 & 0.98 & 17 & 50 & 0 & 0.98 \\
\hline 2 & 40 & 0 & 0.92 & 18 & 50 & 0 & 0.92 \\
\hline 3 & 40 & 0 & 0.86 & 19 & 50 & 0 & 0.86 \\
\hline 4 & 40 & 0 & 0.80 & 20 & 50 & 0 & 0.80 \\
\hline 5 & 40 & 21 & 0.98 & 21 & 50 & 21 & 0.98 \\
\hline 6 & 40 & 21 & 0.92 & 22 & 50 & 21 & 0.92 \\
\hline 7 & 40 & 21 & 0.86 & 23 & 50 & 21 & 0.86 \\
\hline 8 & 40 & 21 & 0.80 & 24 & 50 & 21 & 0.80 \\
\hline 9 & 40 & 14 & 0.98 & 25 & 50 & 14 & 0.98 \\
\hline 10 & 40 & 14 & 0.92 & 26 & 50 & 14 & 0.92 \\
\hline 11 & 40 & 14 & 0.86 & 27 & 50 & 14 & 0.86 \\
\hline 12 & 40 & 14 & 0.80 & 28 & 50 & 14 & 0.80 \\
\hline 13 & 40 & 7 & 0.98 & 29 & 50 & 7 & 0.98 \\
\hline 14 & 40 & 7 & 0.92 & 30 & 50 & 7 & 0.92 \\
\hline 15 & 40 & 7 & 0.86 & 31 & 50 & 7 & 0.86 \\
\hline 16 & 40 & 7 & 0.80 & 32 & 50 & 7 & 0.80 \\
\hline
\end{tabular}

Four different ratios of $V / V_{\mathrm{c}}(0.98,0.92,0.86$ and 0.8$)$ with the same distances were selected to study the effect of different flow conditions. In addition, in order to evaluate the effect of inclination of piers at the same experimental conditions, the scour tests around vertical pier were designed according to the conditions of inclined pier tests. The tests are listed in table 1.

First, the pier was placed in the channel with desired angle and then was fully surrounded by sediment. Through using a cart located in the top rails of channels and in which a metal plate has been provided at the bottom, sediments were completely flatted. Figure 5 shows a schematic view of flatted bed and inclined pier toward downstream before test running.

Before test running, the inflow water into the channel gradually increased to reach the assumed discharge. After test running and achieving the conditions of relative equilibrium, the pump was set off and existing water in the channel was drained slowly so that no changes were made on the bed profile. After passing several hours and discharging of

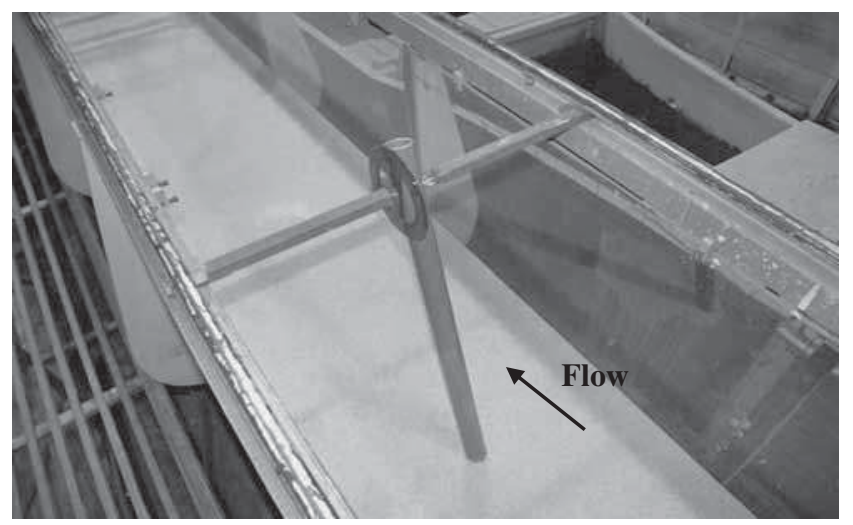

Figure 5. Typical flat bed and inclination pier. water from the channel, the bed profile around the pier and maximum scour depth were recorded using depth gauge.

Determination of initial motion conditions and critical velocity are required in the main tests. For this purpose, first, the values of $V_{\mathrm{c}}$ were determined using preliminary tests and then, corresponding values of $u_{* c}$ with $V_{\mathrm{c}}$ were computed by the following equation [14].

$$
\frac{V}{u_{*_{C}}}=5.75 \log \left(5.53 \frac{d_{\circ}}{d_{50}}\right) .
$$

In this equation $d_{0}$ upstream flow depth, $d_{50}$ sediment average diameter, $V_{\mathrm{c}}$ critical average velocity in initial motion and $u_{*_{C}}$ critical shear velocity of sediment.

The results indicated that $u_{*_{C}}$ obtained from the test has a good agreement with that of from Shields chart and accordingly were accepted. $V_{c}$ can be computed using $u_{*_{C}}$ and upstream depth.

To calculate the equilibrium time, a 100-hour-test was conducted to determine changes of scour depth in relation with time, as shown in figure 6.

Based on the criterion proposed by Melville \& Chiew [15], equilibrium time occurs when the changes of scour depth is less than $5 \%$ of pier diameter within $24 \mathrm{~h}$. In accordance with carried out test, the equilibrium time was computed $70.8 \mathrm{~h}$. However, due to decrease in the changes rate of the specified equilibrium time after $18 \mathrm{~h}$, this time was considered as relative equilibrium time in all tests.

\section{Results}

\subsection{Effect of piers inclined on bed topography}

Figure 7 shows the effect of pier inclination toward downstream on the bed topography in different inclined angles. As 


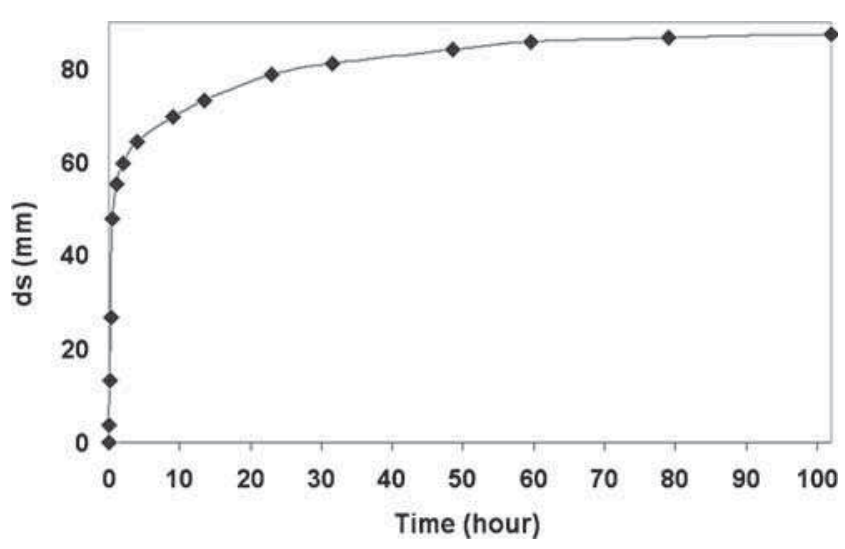

Figure 6. Equilibrium time diagram.

it is apparent, at the same conditions, increase in the inclination angle resulted in significant decrease in the dimension of sediment ridge and scour hole. In effect, this represents decrease of scour mechanism due to the increase of inclination angle. Among mechanisms affected by inclination, it can be mentioned to down flow which is discussed in the following paragraphs. According to figure 7, by increasing the inclination angle of the bridge pier, it was observed that an area with low velocities is resulted downstream and it is one of the factors decreasing scour depth.
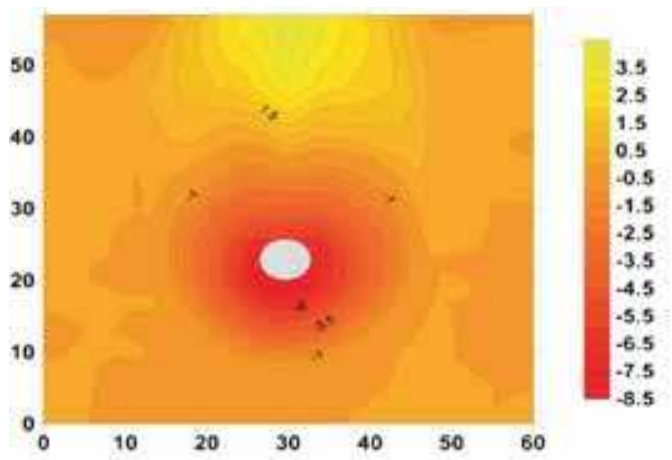

(a)

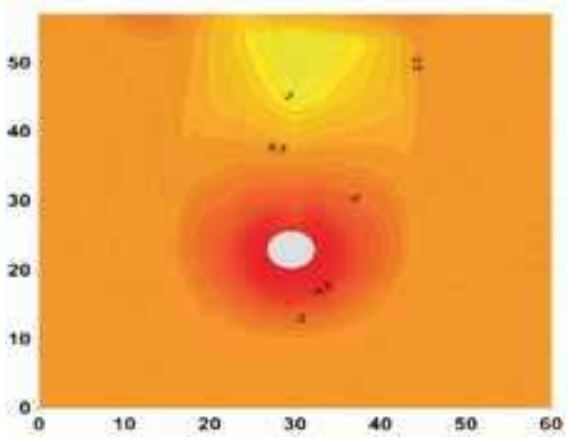

(c)

\subsection{Effect of piers inclined on longitudinal and lateral profile}

Comparison between longitudinal and lateral profiles for different inclination angles $(\beta)$ under two different flow conditions $\left(V / V_{\mathrm{c}}\right.$ of 0.8 and 0.98$)$ have been depicted in figure 8 . The most striking feature in this figure is decrease of scour depth with the increase in the inclination angle under all flow conditions. Also, decrease in the dimensions of scour hole and sediment ridge can be observed in all flow conditions. It is interesting to mention that erosion mainly occurred at lateral walls (based on the lateral profiles) and hole upstream wall (based on the longitudinal profiles).

This can be attributed to the steep slope of walls. As scour depth increases, these walls become more unstable and consequently sediment sliding and erosion occur. On the other hand, the profiles of downstream walls are close to each other and this is more evident in the initial motion. In accordance with figure 8(d), width increase in the hole top levels at $V / V_{\mathrm{c}}$ equal to 0.98 (at a condition near to initial motion) can be observed during all inclination angles. In general, it can be concluded that increase of inclination angle may lead to decrease in the development of scour. Moreover, it can be stated that by increasing the inclination angle of the bridge pier, the bridge pier' cross section at the part touching the bed is more of an aerodynamics shape. In fact, the cross section is changed from a circle into an oval, and this causes a decrease in the local scour hole volume, thus decreasing the

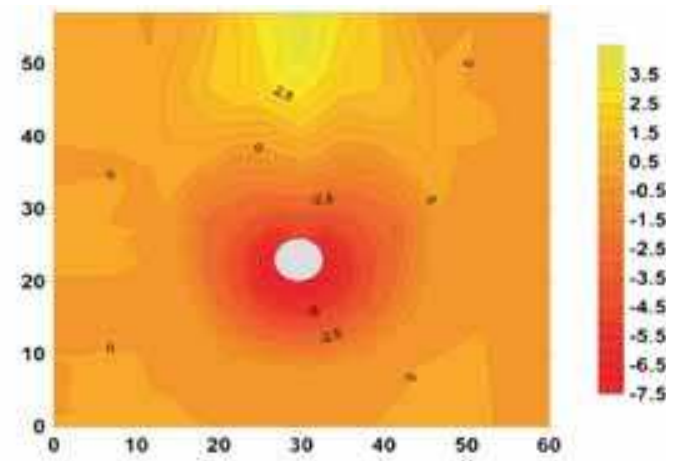

(b)

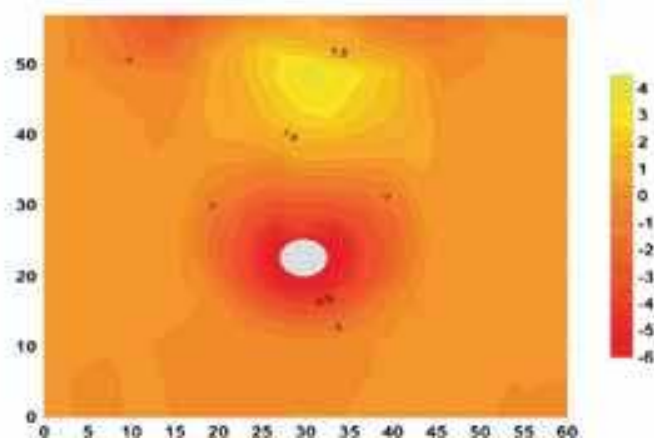

(d)

Figure 7. The effect inclination pier into downstream on bed topography (for example $D=5 \mathrm{~cm}$ and $V / V_{\mathrm{c}}=0.86$ ): (a) vertical pier, (b) 7 degree, (c) 14 degree and (d) 21 degree inclination. 


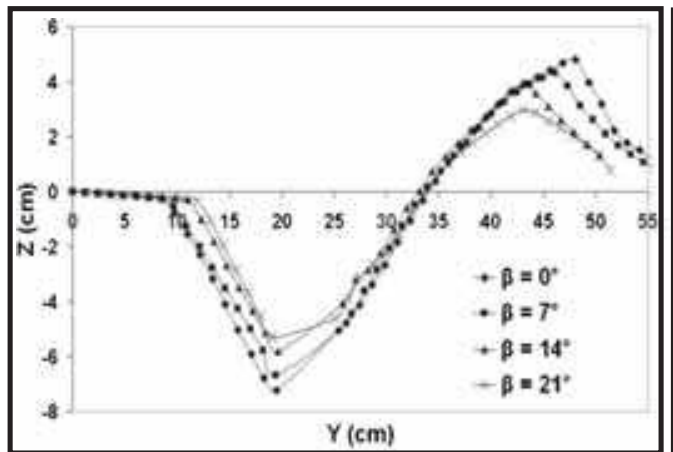

(a)

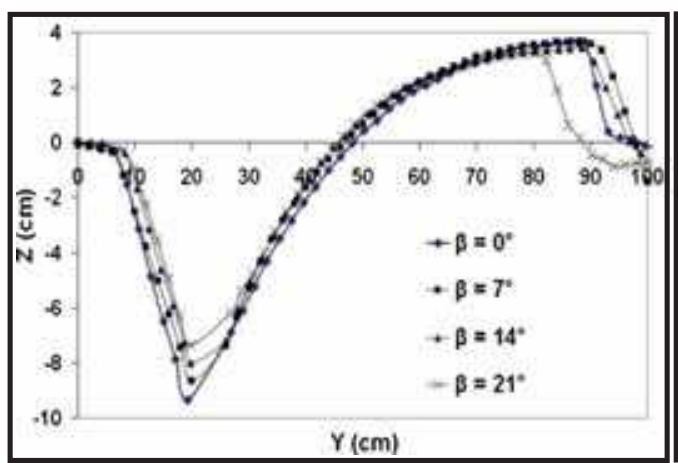

(c)

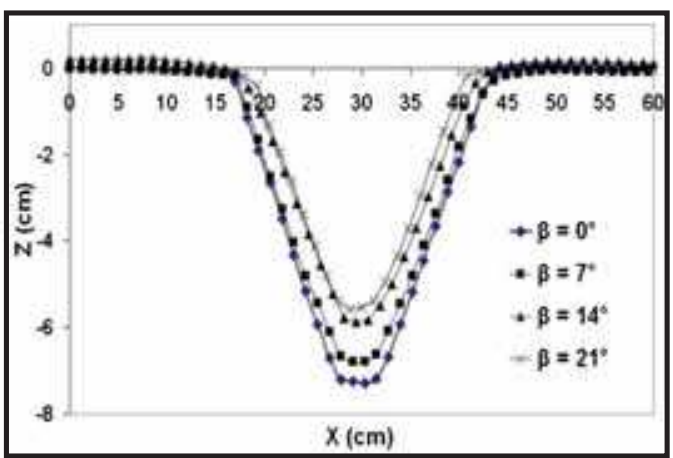

(b)

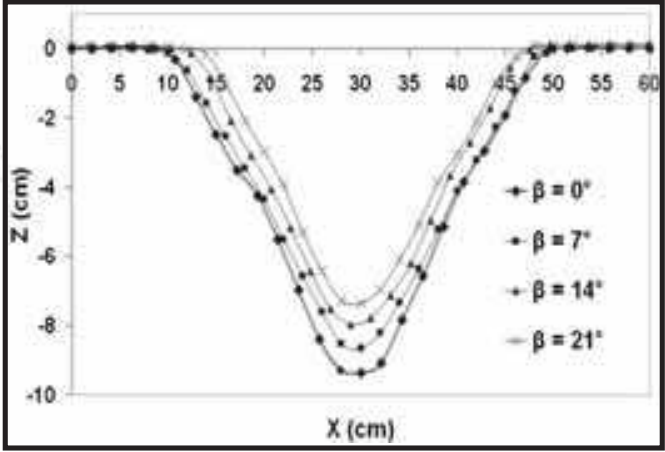

(d)

Figure 8. Comparison between longitudinal and lateral profile for different angles of inclination pier; (a) and (b) $V / V_{\mathrm{c}}=0.8$, (c) and (d) $V / V_{\mathrm{c}}=0.98$.

maximum scour depth. Also, due to expansion of the low velocity area downstream of the bridge pier at angles with more inclination, the sedimentation increases downstream.

\subsection{Effect of flow on longitudinal and lateral profile}

Comparison between longitudinal and lateral profiles for a $14^{\circ}$ inclined pier and under different flow conditions are shown in figure 9. Increase of scour depth as a result of increase in the $V / V_{\mathrm{c}}$ is clear. Based on the longitudinal and lateral profiles, increase in the scour hole dimension can be seen which represents the migration of more volumes of sediments due to increase of $V / V_{\mathrm{c}}$.

It is also noteworthy that height of sediment ridge has decreased by increase of flow rate. This decrease is mainly due to the increase of erosion effects of flow on the sediment ridge.

Furthermore, an increase was seen in the hole width at the top of scour hole. As can be seen in figure 9(b), this difference is more sensible in the high flow rates.

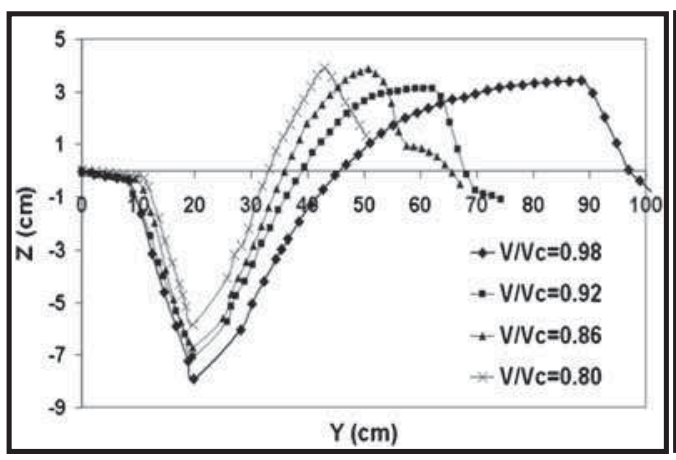

(a)

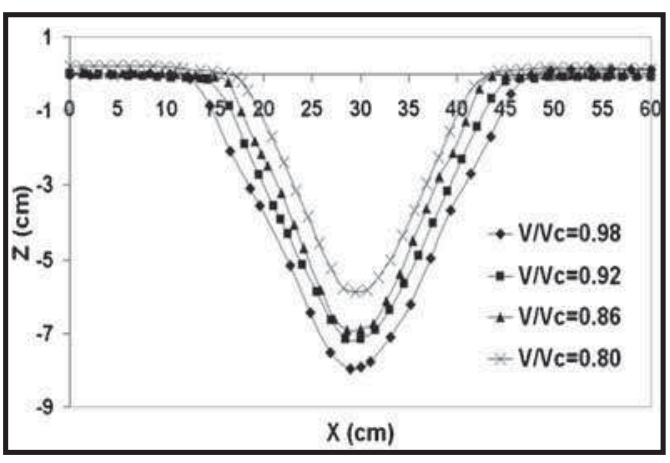

(b)

Figure 9. Caparison between longitudinal and lateral profile at 14 degree of inclination pier under different conditions; (a) longitudinal and (b) lateral profile. 


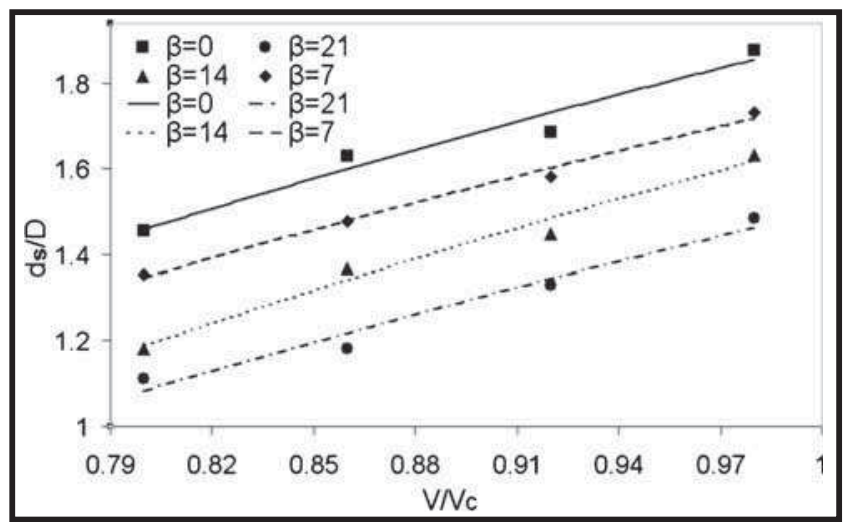

Figure 10. Effect of inclination pier at different angles on maximum of scour depth under different conditions $(D=5 \mathrm{~cm})$.

\subsection{Study effect of inclined piers on maximum depth scour}

At first glance to the test results, it can be observed that a notable decrease in the scour depth occurs as a result of increase in the inclination angle of pier. Figure 10 shows the results of maximum relative scour depth $d_{\mathrm{s}} / D$ in terms of $V / V_{\mathrm{c}}$ relevant to pier with diameter $5 \mathrm{~cm}\left(D\right.$ and $d_{\mathrm{s}}$ are pier depth and relative scour depth, respectively). In this figure, the top line is related to vertical pier and bottom lines are related to piers with $7^{\circ}, 14^{\circ}$ and $21^{\circ}$ inclination toward downstream.

According to this figure, drastic decrease in the scour depth with increase in the inclination angle can be observed in all flow conditions. In general, it can be concluded that these decreases have been occurred at all $V / V_{\mathrm{c}}$ with the proportion.

As expected, increase of $V / V_{\mathrm{c}}$ up to reaching initial motion limit $\left(V / V_{\mathrm{c}}=0.98\right)$ cause increase in the scour depth.

The effect of 21 degree inclination of pier toward downstream on the maximum scour depth for different flow conditions and pier diameter is illustrated (figure 11). As it can be seen clearly, there is no relation between variations of maximum scour depth with pier diameter.

Ettema et al [16] found through evaluation of different pier diameters that increase in the pier diameter $(D)$ leads to increase and decrease in the scour depth $\left(d_{\mathrm{s}}\right)$ and variations trend of $d_{\mathrm{s}} / D$, respectively. This trend illustrated in figure 11 is evident in the following charts. It should be mentioned that one of the most important mechanisms in the local erosion around piers is weak vortex and the strength of them is directly proportional to the frequency of vortex formation behind the piers. They stated that this phenomenon is mainly due to the relative decrease in the strength of weak vortexes to erode and lift sediments around pier and this is in turn due to the frequency change of produced vortexes behind pier. They believed that increase of pier diameter may lead to decrease in the frequency of produced vortexes and

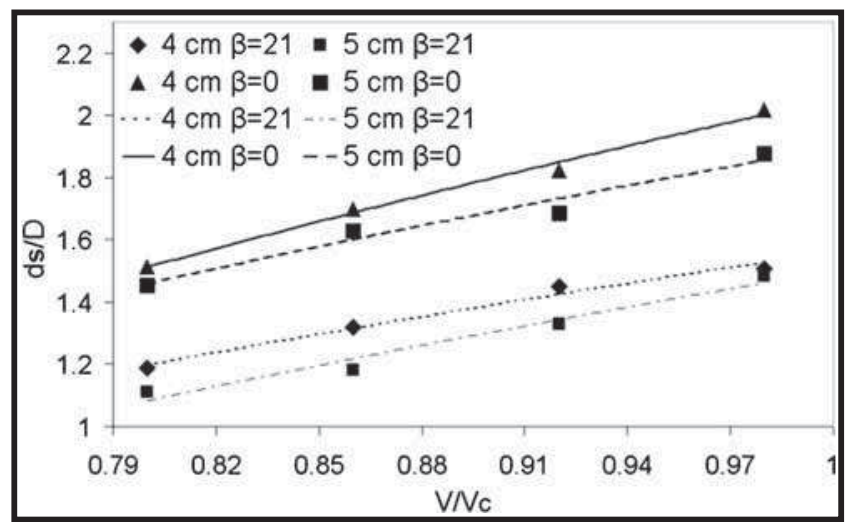

Figure 11. Effect of 21 degree inclination pier on maximum of scour depth under flow different conditions and different diameter of pier.

consequently this causes in decrease in the relative strength for erosion.

Figure 11 shows the significant decrease in the relative scour depth for a pier with $21^{\circ}$ inclination toward downstream. This decreasing trend can be clearly observed in all velocity ratios. This is mainly due to assigned to the decrease of vertical component of velocity on the pier wall and existence of tangential component of velocity on the pier (figure 12).

As it cited in figure 12, the profile of upstream flow velocity is almost uniform within region A and it approaches to zero in the vicinity of the bottom (region B) due to the properties of no sleep the fluid. This velocity profile becomes zero after encountering with pier nose and head velocity converts into pressure head. The pressure head diagram on the vertical pier is presented in the following figure.

As it can be seen in the region $\mathrm{B}$, because of the existence of velocity gradient, corresponding pressure gradient form at stagnation line in the pier nose and is the cause of down flow. After inclination of pier toward downstream, velocity vectors are resolved into normal and tangential components and

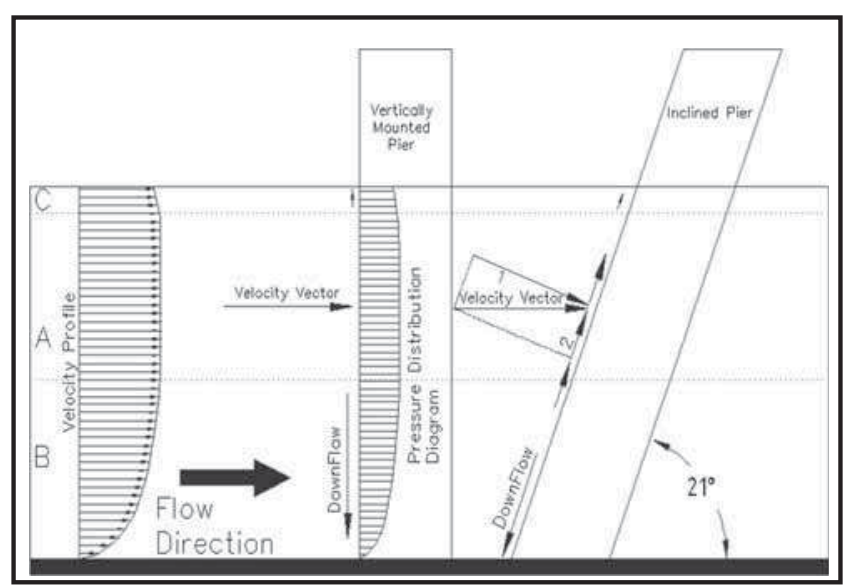

Figure 12. Schematic view of formation down flow and vector velocity in front of vertical pier and inclination pier into downstream. 
Table 2. Change percent of scour depth between 21 degree of inclination pier and vertical pier.

\begin{tabular}{lcccc}
\hline$V / V_{\mathrm{c}}=0.98$ & $V / V_{\mathrm{c}}=0.92$ & $V / V_{\mathrm{c}}=0.86$ & $V / V_{\mathrm{c}}=0.80$ & Diameter of pier \\
\hline$-23.5 \%$ & $-23.24 \%$ & $-22.49 \%$ & $-20.54 \%$ & $4 \mathrm{~cm}$ \\
$-21.515 \%$ & $-22.54 \%$ & $-23.75 \%$ & $-26.04 \%$ & $5 \mathrm{~cm}$ \\
\hline
\end{tabular}

the magnitude of both is less than velocity vector. Accordingly, in addition to pressure gradient due to the converting velocity head vectors 1 into pressure head, an up flow forms by tangential vectors 2 due to the pressure gradient in the opposite direction of down flow. Moreover, in comparison with vertical pier, the rate of down flow due to the pressure gradient is lower. This is because the magnitude of normal component vector 1 is lower than that of the velocity vector of vertical pier. Therefore, decrease of pressure gradient and strength of down flow and also conflict of tangential components of velocity in the opposite direction of down flow can be characterized as the main reasons for decrease of maximum scour depth.

The difference between occurred scour depth and scour depth of vertical pier under different flow conditions has been discussed in table 2. Based on this table, it can be concluded that pier inclination of $21^{\circ}$ toward downstream resulted in relative mean decrease around $23 \%$ in scour depth.

Figure 13 shows the effect of $14^{\circ}$ inclination of pier toward downstream on the maximum scour depth for different flow conditions and pier diameter. Also decrease in the ratio $d_{\mathrm{s}} / D$ by increase of pier diameter can be seen that the reason for that was discussed in the previous sections. Furthermore, decrease of scour depth due to the $14^{\circ}$ inclination of pier is evident for both diameters. With the aim of better understanding, the variations of scour depth in terms of percentage are given in table 3 .

As it is cited, as a result of $14^{\circ}$ inclination of pier, a sensible trend exists in the variations of scour depth. Firstly, the

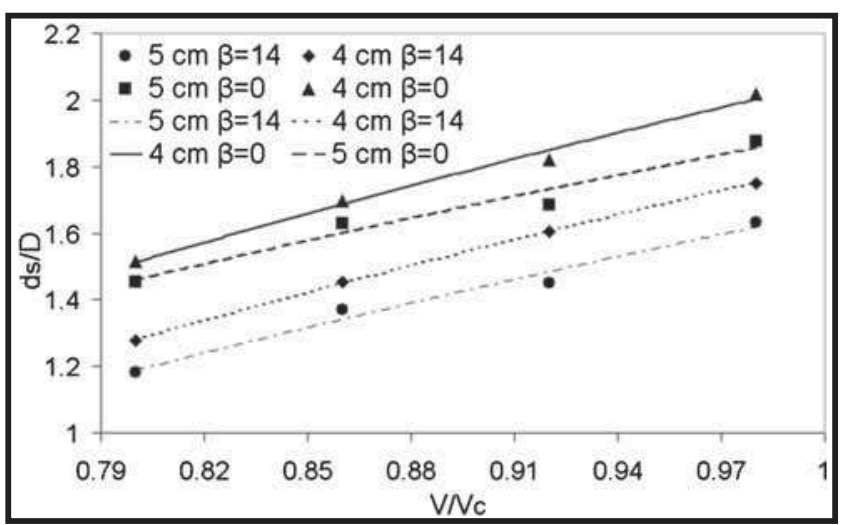

Figure 13. Effect of 14 degree inclination pier on maximum of scour depth under flow different conditions and different diameter of pier. difference in the scour depth is higher in the larger diameter compared to smaller one. Secondly, as the discharge decreases, the difference in the scour depth significantly decreases in both diameters. In general, it can be stated that $14^{\circ}$ inclination of pier caused a $14.5 \%$ scour depth decrease compared to vertical pier.

Figure 14 illustrates the effect of $7^{\circ}$ inclination of pier toward downstream on the maximum scour depth for different flow conditions and pier diameter. The decrease in the ratio $d_{\mathrm{s}} / D$ by increase of pier diameter is also evident for both diameters. Although, decrease in the scour depth is lower in comparison with $14^{\circ}$ and $21^{\circ}$, it is notable.

Table 4 shows the difference between scour depth of pier with $7^{\circ}$ inclination and vertical piers with two different diameters under different flow conditions.

In accordance with this table, it can be seen that the difference between scour depth of vertical and $7^{\circ}$ inclined piers has been reduced. As it is cited, the produced difference in the pier with larger diameter is lower than that of with smaller diameter. Particularly, the decreasing trend in the differences percentage with increase of $V / V_{\mathrm{c}}$ for pier with smaller diameter is clear. It can be observed that $6.8 \%$ decrease in the scour depth occurred as a result of $7^{\circ}$ inclination in the vertical pier.

By viewing the results, it can be stated as a rough approximation that $1 \%$ decrease in the scour depth compared to vertical pier occurs for each degree increase in the inclination angle (this approximation is applicable only for inclination angle lower than $21^{\circ}$ ).

About the flow structure around the inclination bridge pier when scour phenomenon occurs, it can be stated that the flow around the bridge pier is thoroughly turbulent and the flow layers are up flow at high levels and down flow at mid to lower layers. Such down flow streams, upon hitting the bed and forming horseshoe vortexes, cause sediment detachment and they are directed towards the sides of the pier under the effect of the upper layer streams. In addition to the given description, it can be observed in figure 4 that the bridge pier inclination (considering that such inclination is in the stream's direction) helps move the sediment detached from the bed, thus increasing scour around the bridge pier.

\subsection{Comparison between data of vertical piers with many equations of estimation maximum scour depth}

To investigate and compare the results obtained from vertical pier tests with those from empirical relations, some of 
Table 3. Change percent of scour depth between 14 degree of inclination pier and vertical pier.

\begin{tabular}{lcccc}
\hline$V / V_{\mathrm{c}}=0.98$ & $V / V_{\mathrm{c}}=0.92$ & $V / V_{\mathrm{c}}=0.86$ & $V / V_{\mathrm{c}}=0.80$ & Diameter of pier \\
\hline$-12.5 \%$ & $-12.97 \%$ & $-14.2 \%$ & $-15.24 \%$ & $4 \mathrm{~cm}$ \\
$-12.9 \%$ & $-14.45 \%$ & $-16.25 \%$ & $-18.49 \%$ & $5 \mathrm{~cm}$ \\
\hline
\end{tabular}

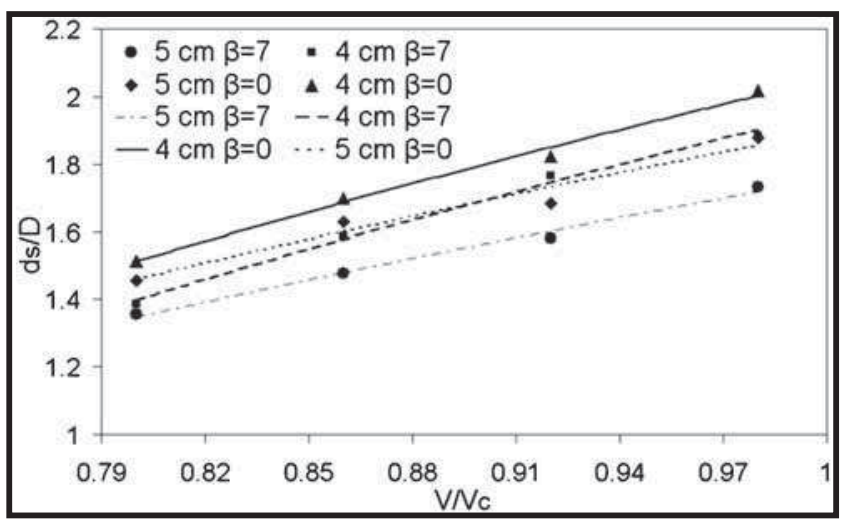

Figure 14. Effect of 7 degree inclination pier on maximum of scour depth under flow different conditions and different diameter of pier.

the well-known relations developed by researchers such as [14, 17-22] have been studied. According to Melville \& Chiew [15], equilibrium time was computed equal to 70.8 h. However, as stated previously, $18 \mathrm{~h}$ was taken as relative equilibrium time corresponding to $85 \%$ of scour equilibrium depth. In other words, the ratio of scour depth at $18 \mathrm{~h}$ to equilibrium scour depth at $70.8 \mathrm{~h}\left(d_{\mathrm{s}} / d_{\mathrm{se}}\right)$ is 0.85 . It is expected that the proposed relations predict the equilibrium scour depth. Thus, it is necessary to divide the observed scour depths to 0.85 so as to close them to equilibrium scour depth $\left(d_{\mathrm{se}}=d_{\mathrm{s}} / 0.85\right)$. In order to compare the computed and observed values, a distinct chart was plotted for each relation in figure 15 in which the horizontal and vertical axes are in terms of estimated and observed scour depth, respectively. The 45-degree-line in this figure is the locus of the points that there is a complete agreement between observed and computed values. It is apparent from the above figure that [17-19] give unsatisfactorily results. This can be attributed to the relative short equilibrium times to derive relations for maximum scour depth. With the aim of better evaluation the accuracy of results obtained from these relations, a statistical method is required. For this purpose, standard error method has been employed to control the accuracy of relations. In this method, lower SE value corresponds to more agreement with predicted values. The calculated results of all methods have been presented in table 5. Based on the results, the [14] relation has the most agreement with the experimental observations. Also as it is illustrated in figure 15 , all points are entirely below the 45-degree-line which shows a reasonable safety factor. One reason for this close adaptation can be assigned to apply Melville relation for equilibrium time of the tests. The main reasons for selecting Melville relation as a compatible relation with experimental observations are that it is more novel in comparison with other relations and has gained more acceptances among engineers.

\subsection{Modify equation for inclined piers}

In this section, the objective is to present a modification coefficient in order to utilize [14] relation to estimate equilibrium scour depth in the inclined piers toward downstream. Melville equation for vertical piers shows that:

$$
d_{S}=K_{y b} K_{I} K_{d} K_{s} K_{\theta}
$$

In this equation:

$$
\begin{array}{llrl}
K_{y b} & =2.4 D & & D / d_{0} \leq 0.7 \\
K_{y b} & =2\left(d D_{0}\right)^{0.5} & & 0.7 \leq D / d_{0} \leq 5 \\
K_{y b} & =4.5 d_{0} & & D / d_{0} \geq 5
\end{array}
$$

$d_{0}$ flow depth at downstream of piers, KI flow intensity coefficient and for uniform sediment is equal to $V / V_{\mathrm{c}}$, $K_{\mathrm{d}}$ sediment dimension intensity, $K_{\mathrm{s}}$ shape coefficient, $K \theta$ impact coefficient of flow to piers [14].

The objective is to propose a coefficient entitled Kin so as to consider the effect of inclination toward downstream in the mentioned relation. For this purpose, scour depths were computed using the above relation for two different pier diameters and different inclined pier conditions. Then, the

Table 4. Change percent of scour depth between 7 degree of inclination pier and vertical pier.

\begin{tabular}{lcccc}
\hline$V / V_{\mathrm{c}}=0.98$ & $V / V_{\mathrm{c}}=0.92$ & $V / V_{\mathrm{c}}=0.86$ & $V / V_{\mathrm{c}}=0.80$ & Diameter of pier \\
\hline$-5 \%$ & $-5.41 \%$ & $-6.51 \%$ & $-7.28 \%$ & $4 \mathrm{~cm}$ \\
$-7.53 \%$ & $-7.51 \%$ & $-7.51 \%$ & $-7.53 \%$ & $5 \mathrm{~cm}$ \\
\hline
\end{tabular}



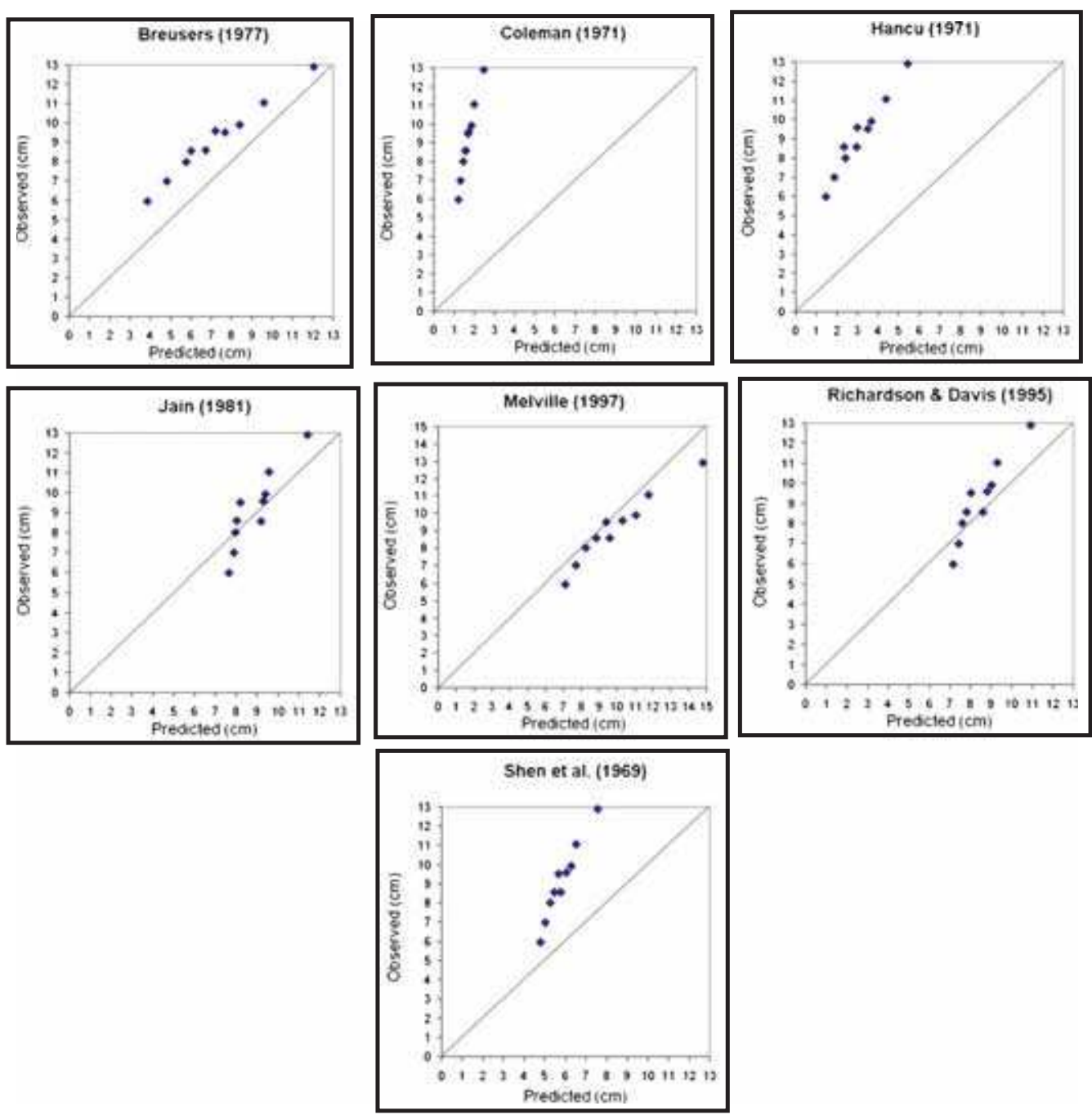

Figure 15. Comparison between estimation depth of scour with observe value of vertical pier tests.

obtained values were divided into corresponding observed values to obtain the required decrease ratio of scour depth to modify the relation. Finally, for each inclination angle, a curve was fitted to the obtained points. Figure 16 shows the variations of Kin in terms of $V / V_{\mathrm{c}}$. The charts appeared orderly from top to bottom are related to inclination angle of $7^{\circ}, 14^{\circ}$ and $21^{\circ}$. For those angles between these three angles, interpolation can be used and the value of Kin should be read from vertical axis. It is recommended to use this chart for inclination angles up to $21^{\circ}$. Furthermore, the value of Kin for inclination angles lower than $7^{\circ}$ can be assumed to be 1 due to the minor difference in the scour depths. However, this chart is only applicable for flow condition between $V / V_{\mathrm{c}}$ of 0.8 and initial motion and beyond this range is not recommended. Hence, the modified Melville relation for inclined pier toward downstream is described as follows:

$$
d_{S}=K_{y b} K_{I} K_{d} K_{S} K_{\theta} \times K_{i n}
$$

Based on the new relation, the values of scour depth have been estimated for inclined pier and compared with observed values. SE statistical test gave a satisfactory value of 0.042 . In addition, estimated values versus observed ones have been compared in figure 17. As can be seen, the scattering of points is around the 45-degree-line. This represents the appropriate estimate of scour depth in this inclination angle.

Table 5. Results standard error on equations.

\begin{tabular}{lccccccc}
\hline & $\begin{array}{c}\text { Shen } \text { et al } \\
{[17]}\end{array}$ & $\begin{array}{c}\text { Coleman } \\
{[18]}\end{array}$ & $\begin{array}{c}\text { Hancu } \\
{[19]}\end{array}$ & $\begin{array}{c}\text { Breusers } \text { et al } \\
{[20]}\end{array}$ & $\begin{array}{c}\text { Jain } \\
{[22]}\end{array}$ & $\begin{array}{c}\text { Melville } \\
{[14]}\end{array}$ \\
\hline S.E. & 0.379 & 0.832 & 0.665 & 0.215 & 0.114 & 0.124 & 0.105 \\
\hline
\end{tabular}




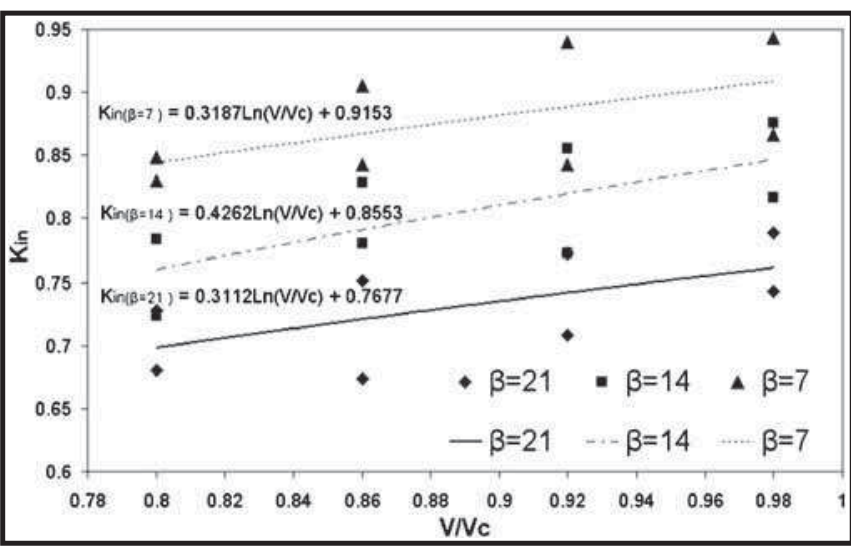

Figure 16. Inclination coefficient of pier in to downstream for modify Melville equation.

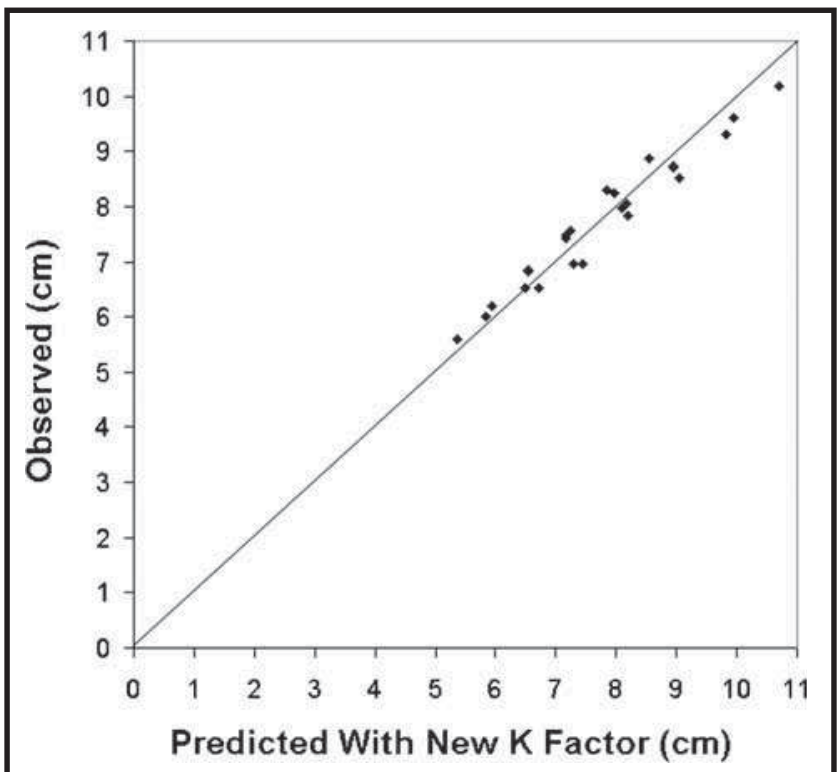

Figure 17. Comparison between estimation depth of scour by Eq. (3) with observe value.

\section{Conclusions}

The main results of this experimental study are:

- At the same conditions, increase in the inclination angle resulted in significant decrease in the dimension of sediment ridge and scour hole. In effect, this represents decrease of scour mechanism due to the increase of inclination angle.

- A significant decrease in the scour depth with increase in the inclination angle under all flow conditions is apparent. Indeed, these decreases have been occurred at all $V / V_{\mathrm{c}}$ with the proportion. By viewing the results, it can be stated as a rough approximation that $1 \%$ decrease in the scour depth compared to vertical pier occurs for each degree increase in the inclination angle (this approximation is applicable only for inclination angle lower than $21^{\circ}$ ).

- Erosion mainly occurred at lateral walls and hole upstream wall.

- Dimensions of scour hole and sediment ridge for all inclination angles and pier diameter is highly affected by flow rate.

- Increase in the pier diameter $(D)$ leads to increase and decrease in the scour depth $\left(d_{\mathrm{S}}\right)$ and variations trend of $d_{\mathrm{s}} / D$. This shows the effect of diameter changes on the scour mechanisms around pier.

- Melville [14] relation has the most agreement with the experimental observations. Therefore, it was modified to predict maximum scour depth under inclination of pier toward downstream using inclined pier data.

\section{References}

[1] Dey S 1995 Three-dimensional vortex flow field around a circular cylinder in a quasi-equilibrium scour hole. Sadhana 20(6): 871-885

[2] Dey S 1999 Time-variation of scour in the vicinity of circular piers. In: Proceedings of the ICE-Water Maritime and Energy. $67-75$

[3] Muzzammil M, Gangadharaiah T and Gupta A K 2004 An experimental investigation of a horseshoe vortex induced by a bridge pier. In: Proceedings of the ICE-Water Maritime and Energy. 109-119

[4] Bozkus Z and Yaldiz O 2004 Effects of inclination of bridge piers on scouring depth. J. Hydraul. Eng.-ASCE 130(8): 827832

[5] Lee T L, Jeng D S, Zhang G H and Hong J H 2007 Neural network modeling for estimation of scour depth around bridge piers. J. Hydrodyn. Ser. B 19(3): 378-386

[6] Lee S and Sturm T 2009 Effect of sediment size scaling on physical modeling of bridge pier scour. J. Hydraul. Eng.ASCE 135(10): 793-802

[7] Izadinia E, Heidarpour M and Schleiss A J 2013 Investigation of turbulence flow and sediment entrainment around a bridge pier. Stoch. Environ. Res. Risk A 27(6): 1303-1314

[8] Khosronejad A, Kang S and Sotiropoulos F 2012 Experimental and computational investigation of local scour around bridge piers. Adv. Water Resour. 37: 73-85

[9] Keshavarzi A, Melville B and Ball J 2014 Three-dimensional analysis of coherent turbulent flow structure around a single circular bridge pier. Environ. Fluid Mech. 14(4): 821-847

[10] Aghaee-Shalmani Y and Hakimzadeh H 2014 Experimental investigation of scour around semi-conical piers under steady current action. Eur. J. Environ. Civil Eng. 19(6): 1-16

[11] Chiew Y M and Melville B W 1987 Local scour around bridge piers. J. Hydraul. Eng.-ASCE 25(1): 15-26

[12] Ettema R E 1980 Scour at bridge piers. Rep. No. 236, School of Engineering, the University of Auckland, Auckland, New Zealand

[13] Raudkivi A J and Ettema R 1983 Clear-water scour at cylindrical piers. J. Hydraul. Eng.-ASCE 109(3): 339-350

[14] Melville B W 1997 Pier and abutment scour: Integrated approach. J. Hydraul. Eng.-ASCE 123(2): 125-136 
[15] Melville B W and Chiew Y M 1999 Time scale for local scour depth at bridge piers. J. Hydraul. Eng.-ASCE 125(1): 59-65

[16] Ettema R, Kirkil G and Muste M 2006 Similitude of large scale turbulence in experiments on local scour at cylinders. $J$. Hydraul. Eng.-ASCE 132(1): 33-40

[17] Shen H W, Schneider V R and Karaki S S 1969 Local scour around bridge piers. J. Hydraul. Eng. Div.-ASCE 95(HY6): 1919-1940

[18] Coleman N L 1971 Analyzing laboratory measurements of scour at cylindrical piers in sand beds. In: Proceedings of 14th IAHR World Conference. (Paris, Int. Ass. Hydro-Env. Eng. Res.) 196-211
[19] Hancu S 1971 Sur le calcul des affouillements locaux dams la zone des piles des ponts. In: Proceedings of 14th IAHR World Conference. (Paris, Int. Ass. Hydro-Env. Eng. and Res.) 299313

[20] Breusers H N C, Nicollet G and Shen H W 1977 Local scour around cylindrical piers. J. Hydraul. Res.-IAHR 15(3): 211252

[21] Richardson E V and Davis S R 1995 Evaluating scour at bridges. Rep. No. 18, Hydraulic Engineering Circular, U.S. Department of Transportation, Federal Highway Administration, Washington

[22] Jain S C 1981 Maximum clear-water scour around cylindrical piers. J. Hydraul. Eng.-ASCE 107(5): 611-625 